\title{
IMPROVING TRADITIONAL EARNED VALUE MANAGEMENT BY INCORPORATING STATISTICAL PROCESS CHARTS
}

\author{
Sou-Sen Leu \\ Dept. of Const. Engrg. \\ National Taiwan Univ. of \\ Science and Technology \\ P.O.Box 90-130, Taipei, \\ Taiwan, 10672 \\ Republic of China. \\ leuss@mail.ntust.edu.tw
}

\author{
You-Che Lin \\ Dept. of Const. Engrg. \\ National Taiwan Univ. of \\ Science and Technology \\ P.O.Box 90-130, Taipei, \\ Taiwan, 10672, \\ Republic of China.
}

\author{
Tao-An Chen \\ Dept. of Const. Engrg. \\ National Taiwan Univ. of \\ Science and Technology \\ P.O.Box 90-130, Taipei, \\ Taiwan, 10672, \\ Republic of China.
}

\author{
Yann-Yih Ho \\ Dept. of Const. Engrg. \\ National Taiwan Univ. of \\ Science and Technology \\ P.O.Box 90-130, Taipei, \\ Taiwan, 10672, \\ Republic of China.
}

\begin{abstract}
The earned value management (EVM) approach is considered to be the most objective method available in the measurement of project performances. Nevertheless, the method is limited and does not directly account for variation in individual performance values about a normal or natural level of project performances. Because of that, conventional EVM may cause some project managers to ignore the information that it can provide about the performance trends of their projects as well as their causes and effects. This paper attempts to refine and improve the performance of traditional EVM by the introduction of statistical control chart techniques. Individual control charts are used as tools to monitor variation in performances so that adverse changes can be detected in a timely manner. This allows analysis of in-progress project cost and schedule trends and highlights possible needs for corrective action. In conclusion, the proposed SPC control chart techniques used in EVM can effectively assist managers to timely monitor and manage project performance.
\end{abstract}

Keywords: project performance, earned value, statistical control charts, cause-and-effect analysis

\section{INTRODUCTION}

The earned value management (EVM) method has been used to manage project scope, schedule, and budget worldwide for a long time. EVM is considered as a powerful tool that supports the management of project scope, schedule, and budget. It is a powerful approach for quantitative measure of work performance in terms of cost deviation and schedule deviation and for quantitatively estimating actual completion time and actual cost at completion. Traditional EVM monitoring of project performances is based on the budgeted cost of work performed (BCWP), budgeted cost of work scheduled (BCWS) and actual cost of work performed (ACWP). And then, the cost variance (CV) and schedule variance (SV), or cost performance index (CPI) and schedule performance index (SPI) are calculated to measure the project performances. CPI and SPI are usually expressed in the periodic or cumulative way. Although that the EVM approach is considered to be the most objective method available in the measurement of project performances, the method is limited and does not directly account for variation in individual performance values about a normal or natural level of project performances. A gap exists between the use of existing methods and the availability of an appropriate methodology that specifically addresses variation in performances. The nature of this variation when depicted in the cumulative way is not directly apparent and only a slight wavelike pattern is evident. This is not relevant were the EVM approach used, since only the final cumulated value is required, but it is important if a causal connection between individual project performance values and events or conditions were to be considered. Given the nature of the variation in project performance, it would appear that different types of events or conditions are operating, which may or may not be attributable to project managers. The above-mentioned situations can obviously be improved by providing the construction industry with statistical process control (SPC) method which supports the functions of continuous monitoring on the variation of project performances and effective analysis of cause and effect to provide corrective action recommendations. An overall scheme of preventive performance management by incorporating SPC is shown in Fig. 1. It consists of four main components: 1) control chart plotting; 2) automatic control chart pattern recognition; 3) short-term trend prediction; and 4) cause and effect analysis. The algorithms and the operational procedures of each component will be surveyed in the future research. This paper mainly describes the basic concept and techniques of the SPC-based EVM.

This paper adopted the concept of SPC to analyze project performance data: CPI and SPI. In Section 2, we discuss the concepts of EVM and SPC used in this study. Section 3 explains, in detail, the stepwise procedure for combining SPC techniques for evaluating project performance trends and assignable causes of adverse trends. Conclusions are drawn and future directions are indicated in the final section. 


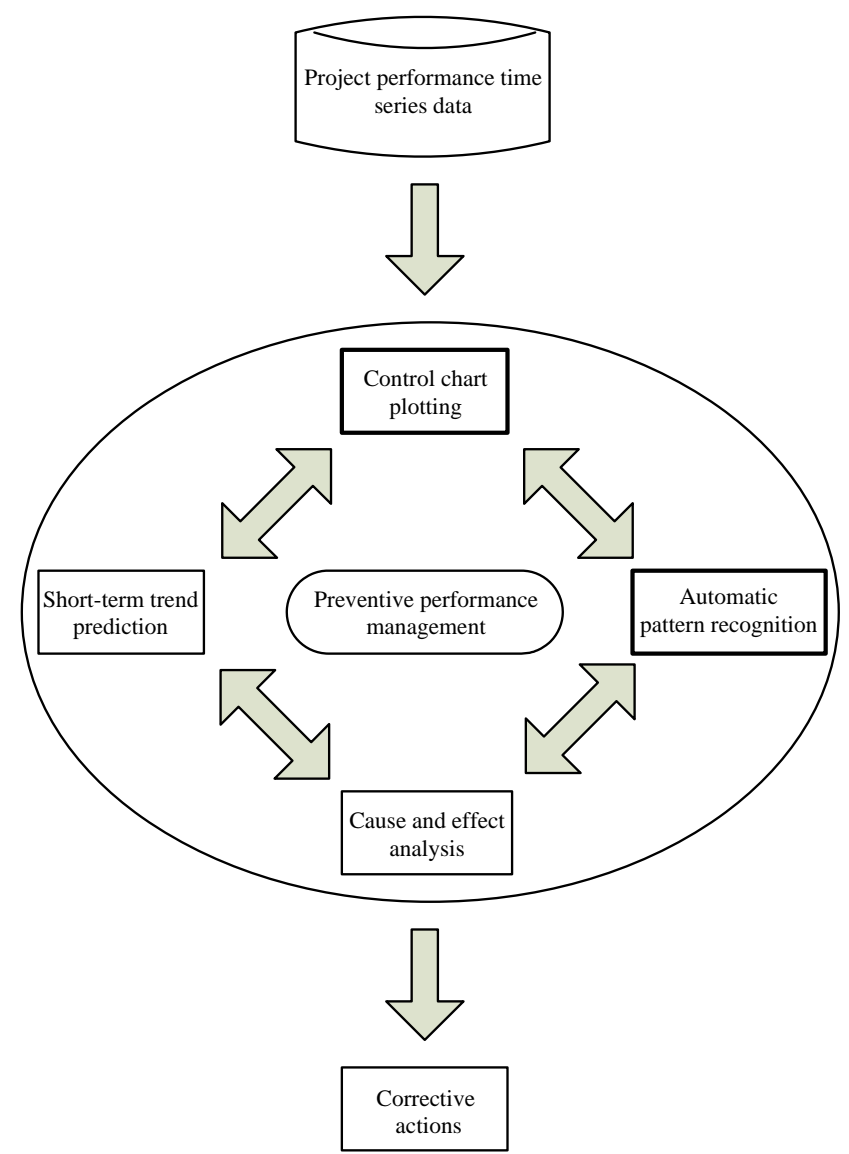

Fig. 1 Overall Scheme of SPC-based Performance Management System

\section{METHODOLOGIES}

\subsection{Earned Value Management}

The basic concept of EVM has not changed for past three decades since its inception [2,5,6,7,11]. EVM is an established method for the evaluation and financial analysis of project performances throughout project life cycle so that project managers and the organization can take timely actions in response to indicators of poor performance and increase the opportunities for project success [5,6]. Nevertheless, due to the over-complication of EVM methodologies and procedures, as well as massive efforts involved in data gathering, reporting and integrated information analysis, it is underused [2,7]. In addition to the above-mentioned deficiencies, there is one more deficiency in traditional EVM. It relates purely to cost and schedule performances only at the report date and no account is taken in time sequence. Generally, only single cost and schedule status at specific report date and completion forecast are conducted to represent project performance. The variation in individual performance values is not directly evaluated in most cases. The persistent performance variations and their consequences are not detected in traditional EVM. To overcome the limitations of traditional EVM, SPC techniques are adopted in this research.
The kernel of EVM is earned value (EV). EV is basically the budget for the completed work up to a point in time [2,6]. Earned value is also known as budgeted cost of work performed (BCWP). It is usually expressed in dollars and can be periodic or cumulative. In addition to BCWP, there are two basic data elements on the EVM report that are central to proper planning, measurement, and analysis: budgeted cost of work scheduled (BCWS) and actual cost of work performed (ACWP). BCWS is the budget for work scheduled to be completed. ACWP is the actual cost incurred in accomplishing the work within a given time period. Nearly all of the other data items in EVM may be derived from these three data items.

Two important performance indices are CPI and SPI. The indices are ratios. During project execution, CPI and SPI provide information about performance efficiency. CPI is the efficiency of achieving earned value with respect to the actual costs (CPI=BCWP/ACWP). SPI is the efficiency of achieving earned value with respect to the performance baseline (SPI=BCWP/BCWS). In the above formulas, 1.00 indicates that performance is on target. More than 1.00 indicates excellent performance; and less than 1.00 indicates poor performance. In practice, the warning level of SPI is generally drawn at 0.90 in Taiwan. When the index reaches within 0.90 and 1.00 , more intensive monitoring measurements need to be taken. When the index reaches below 0.90 , corrective actions need to be taken to avoid losing control of project.

\subsection{Statistical Process Chart (SPC)}

SPC are one of major statistical process control tools for performing statistical process control $[9,10,12,13,14]$. The SPC technique was first proposed in 1924 by Shewhart at Bell Lab $[3,9,10,12]$. The main purpose of SPC is used as a feedback system that aids in preventing defects rather than allowing defects to occur. The control chart could graphically depict variation. SPC is used to distinguish variations due to assignable causes from those due to unavoidable chance causes. Based upon the output of SPC, it allows for the elimination of assignable causes and the reduction of common cause variation. SPC techniques have been intensively used for quality control in the manufacturing industry $[3,9,10,13]$. SPC technique was also used as an aid to monitor environmental performance and software development $[4,9,14]$.

There are seven SPC control chart types, each having a specific application [12]. A summary of SPC types is depicted in Fig. 2. Due to only individual datum per run in our case, the control chart technique, Individuals and Moving Range (termed as X-Rm) is used for the study. The formulas of $\mathrm{X}-\mathrm{Rm}$ are depicted in the following. The theoretical principles underlying $\mathrm{X}-\mathrm{Rm}$ are three: 1) samples are from normal distribution; 2) samples are independent and identically distributed; 3) samples are randomly selected. Lipke's research (2002) showed that if the requirement of normal distribution is not satisfied, the analysis and calculated results of control charts may be affected. The data with non-normal distribution need to be 
transformed. The individual control chart (X Chart) is depicted as follows :

Central line $(\mathrm{CL})=$

$\overline{\mathrm{X}}=\frac{\sum X}{k}=\frac{X_{1}+X_{2}+\ldots \ldots+X_{k}}{k}$

Upper control line (UCL) $=$

$\frac{X_{1}+X_{2}+\ldots \ldots+X_{k}}{k}+2.660 \frac{\sum \mid X_{i}-X_{i+1}}{k-n+1}$

Lower control line $(\mathrm{LCL})=$

$\frac{X_{1}+X_{2}+\ldots \ldots+X_{k}}{k}-2.660 \frac{\sum\left|X_{i}-X_{i+1}\right|}{k-n+1}$

where $\bar{X}$ : average of observed data; $k$ : the number of observed data; $n$ : run length ( $n=2$ in our case).

A control chart consists of a central line and two control limits (upper and lower limits). If all process data are plotted within the control limits and without any particular tendency, the process is regarded as being in the controlled state. Control chart patterns provide the information about the state of a process. As stated above, when points fall outside the control limits or show a particular tendency, the process is regarded as being out of control, i.e., there exist assignable causes of variations and they need to be identified for process improvement. There are several ways to classify control chart patterns $[3,9,10,13]$. The rules used in this study to detect control chart trend patterns are based on Western Electric Company edition.

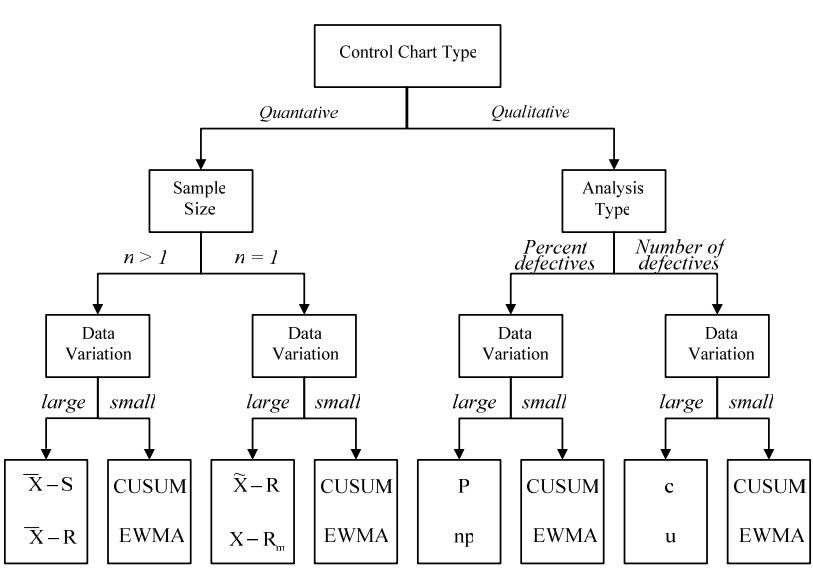

Fig. 2 Architecture of Statistical Control Charts

\section{DATA COLLECTION AND TRANSFORMATION}

Data for the performance evaluation in this paper were taken from an engineering consultant company. The original data set contained 209 records. However, some data were deleted due to incompleteness and vagueness in data, and incompatible data conditions (such as different project types). Furthermore, in order to get higher correct prediction of performance analysis, the uniform distribution of data sets was also crucial. Based upon the above-mentioned data selection principles, there were only 171 data pairs remaining for the performance analysis. The
BCWS, BCWP and ACWP data are collected and analyzed from their budget plans and actual cost summary reports.

To evaluate whether the data set fullfils the principle of normal distribution, Kolmogorov-Smirnov (K-S) test was adopted for the evaluation. K-S test concentrates on the deviations between the hypothesized cumulative distribution function and the observed cumulative histogram. Its basic procedures are: 1) to rank the observations from the smallest to the largest; 2) to define the observed cumulative value $\left.\left(F\left(X_{i}\right)=i / n\right) ; 3\right)$ to compute the largest of the absolute values of the differences between the hypothesized CDF and the observed cumulative histogram evaluated at the observed values in the samples; 4) to compare the test statistic and threshold to decide the acceptance or the rejection of the hypothesis. The level of significance for this case was defined as 0.10 . If the values of calculated level of significance are smaller than 0.10 , the alternative hypothesis $H_{1}$ : not normal distribution was accepted, i.e., samples are not from normal distribution. Table 1 shows that over one-third of performance data do not satisfy the requirement. Lipke's research (2002) showed that if the requirement of normal distribution is not satisfied, the analysis and calculated results of control charts may be affected. In this study, the natural logarithm function was applied for data transformation.

Table 1 K-S Hypothesis Test for Non-normal Distribution

\begin{tabular}{|c|c|c|}
\hline $\begin{array}{l}\text { Performance } \\
\text { Index }\end{array}$ & Number of Projects & Percentage (\%) \\
\hline SPI & 56 & 32.8 \\
\hline CPI & 78 & 45.6 \\
\hline
\end{tabular}

\section{ANALYSIS AND COMPARISON}

171 data pairs of project performances and their related causes were collected for analysis. The natural logarithm function was applied for data transformation. Transformed project performance data were then plotted in the SPC control chart (see Fig. 3). Basic pattern analysis flowchart of the SPC control chart is depicted in Fig. 4. The analysis results of 171 projects are summarized in Table 2 . As seen in Table 2, only 36 SPI-X charts and 32 CPI-X charts are regarded as natural patterns. This is, only around one-fifth projects are in statistical control. Based upon the SPC control chart principles, there exist assignable technical and management causes that appear during the project process. They need to be identified and tackled. To evaluate the output of SPC analysis, traditional EV analysis was executed and its result was compared with SPC results. 


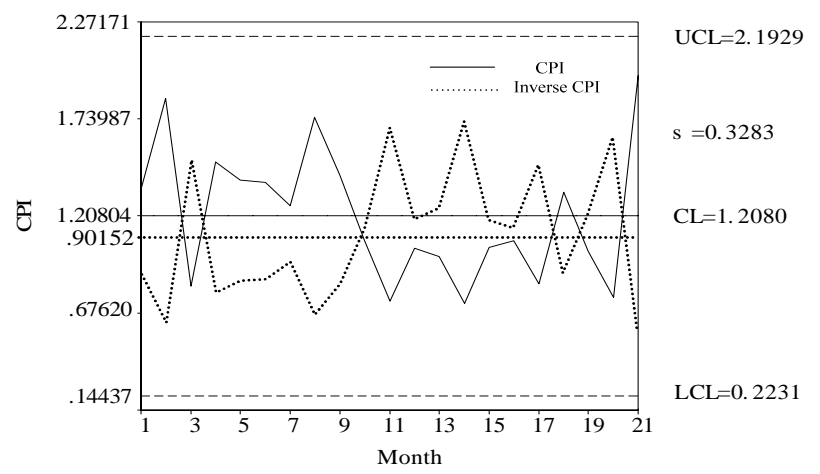

Fig. 3 CPI and Inverse CPI Control Charts

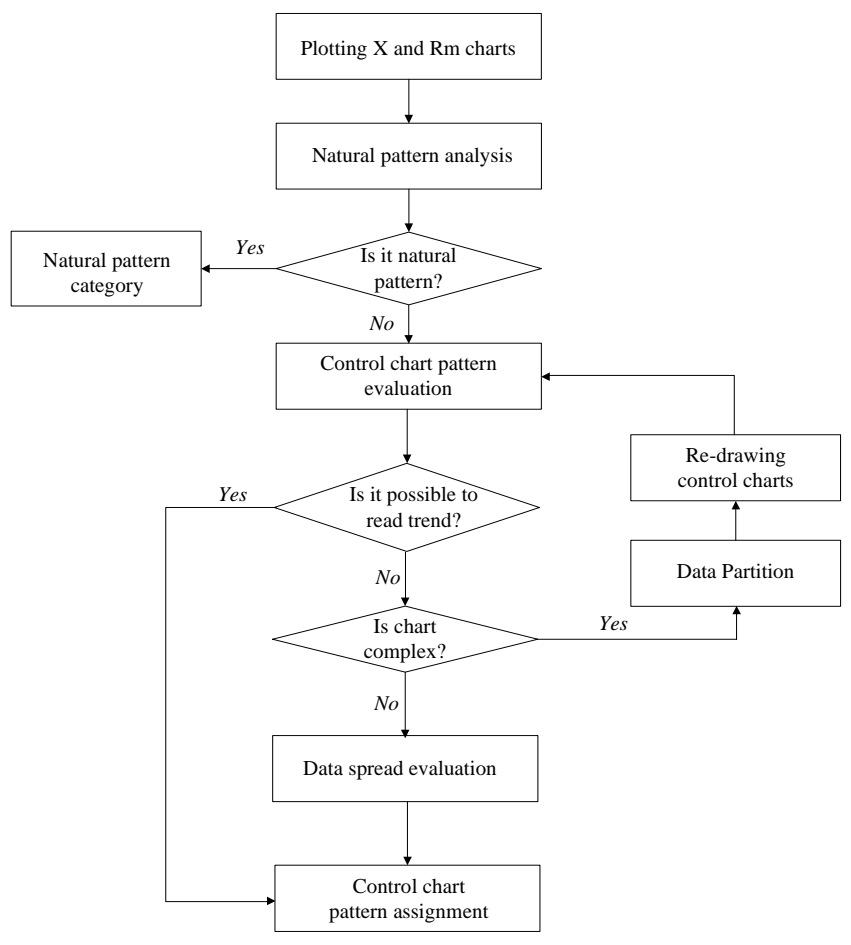

Fig. 4 Flowchart of Pattern Analysis of Control Charts

Traditionally, the construction industry generally sets 0.9 as the performance warning level. 171 projects were classified into 3 groups: in control, mainly in control, and out of control. The projects with all monthly performance indices above 0.9 are regarded as in control. The projects with $20 \%$ monthly performance indices below 0.9 are regarded as mainly in control. Others are regarded as out of control. The analysis results of traditional EV analysis are summarized in Table 3. The majority of the projects are in control or mainly in control. It seems that the project control at the consultant company is excellent. However, based upon the SPC control chart analysis, many projects are not in statistical control (see Table 2). There may exist some assignable causes that affect project performances within the project control cycle.
Table 2 Summary of Control Chart Patterns

\begin{tabular}{|c|c|c|c|c|}
\hline \multirow{2}{*}{ Performance } & \multicolumn{2}{|c|}{$\mathrm{SPI}-\mathrm{X}$} & \multicolumn{2}{|c|}{$\overline{C P I-X}$} \\
\hline & $\begin{array}{c}\text { No. of } \\
\text { Projects }\end{array}$ & $\%$ & $\begin{array}{l}\text { No. of } \\
\text { Projects }\end{array}$ & $\%$ \\
\hline Freaks & 26 & 15.20 & 17 & 9.94 \\
\hline $\begin{array}{l}\text { Gradual Change } \\
\text { in Level }\end{array}$ & 14 & 8.19 & 7 & 4.09 \\
\hline $\begin{array}{l}\text { Grouping or } \\
\text { Bunching }\end{array}$ & 15 & 8.77 & 12 & 7.02 \\
\hline Instability & 25 & 14.62 & 11 & 6.43 \\
\hline Interaction & 16 & 9.36 & 29 & 16.96 \\
\hline Natural Pattern & 36 & 21.05 & 32 & 18.71 \\
\hline $\begin{array}{l}\text { Sudden Shift in } \\
\text { Level }\end{array}$ & 22 & 12.87 & 41 & 23.98 \\
\hline Trends & 17 & 9.94 & 22 & 12.87 \\
\hline Total & 171 & 100 & 171 & 100 \\
\hline
\end{tabular}

Table 3 Summary of Traditional EV Analysis

\begin{tabular}{|l|c|l|l|l|}
\hline \multirow{2}{*}{$\begin{array}{c}\text { Rerformance } \\
\text { Index }\end{array}$} & \multicolumn{2}{|l|}{ SPI } & \multicolumn{2}{l|}{ CPI } \\
\cline { 2 - 5 } & $\begin{array}{l}\text { No. of } \\
\text { Projects }\end{array}$ & $\%$ & $\begin{array}{l}\text { No. of } \\
\text { Projects }\end{array}$ & $\%$ \\
\hline In Control & 43 & 25.15 & 45 & 26.31 \\
\hline Mainly in Control & 112 & 65.50 & 89 & 52.05 \\
\hline Out of Control & 16 & 9.35 & 37 & 21.64 \\
\hline Total & 171 & 100 & 171 & 100 \\
\hline
\end{tabular}

\section{CAUSE AND EFFECT ANALYSIS}

By interviewing project managers and reviewing project historical records, life-cycle stages having poor project performances are summarized in Tables 4. Different control chart patterns own varying causes. For example, for the Freak chart pattern, the causes are mainly from the construction stage, the administration stage, and the land acquisition stage. While the main causes of the gradual change in level pattern are from the construction stage and the bidding process. Overall, some causes simultaneously occur in several control chart patterns, they are the construction stage, the land acquisition stage, the bidding process and the administration stage. For these construction life-cycle stages with frequent cause occurrence, further data collection and analysis are required for detailed causes. Once these causes are identified, corrective measures need to be further analyzed and taken for out-of-control situations if necessary. Periodic review of the status of these causes should be conducted on a regular basis.

\section{CONLCUSIONS AND FURTHER DIRECTIONS}

The quick proliferation and complexity of project performance data indicate the need for a well-organized project performance analysis process. In this paper, a 
detailed quantitative procedure for monitoring and evaluating project performance was described. We show that SPC control chart techniques can be very useful for project performance monitoring and management. The proposed SPC control chart techniques, used in EVM, support effective and in-depth performance trend evaluation and further cause-and-effect analysis. This provides useful information to project managers responsible for monitoring and evaluating project performance. Although the traditional EVM approach is considered to be the most objective method available in the measurement of project performances, the method is limited and does not directly account for variation in individual performance values about a normal or natural level of project performances. A gap exists between the use of existing methods and the SPC-based EVM that specifically addresses variation in performances. The nature of this variation when depicted in the cumulative way is not directly apparent and only a slight wavelike pattern is evident. There are several benefits to this approach. First, the goal of proactive performance management is achieved by integrating EVM with SPC control chart techniques. The SPC-based EVM provides an environment such that project managers can be aware of relevant performance trend issues during the project process. Second, causes for performance variations can be systematically analyzed. Further measures can be taken to reinforce positive trends, stabilize performance or correct for adverse trends. Causes that affect performance trends can be further surveyed. Appropriate corrective measures can be taken to prevent non-compliance during the project execution cycle.

In conclusion, applying SPC control chart principles to EVM opens up many areas of research. First, one needs to continue to analyze and compare various types of SPC control charts. Using more performance data with different project types, it will be necessary to determine the appropriateness of applying SPC to EVM. Second, better understanding of cause and effect relationships on construction performance trends is needed. The appropriateness of corrective measures depends on whether the causes of performance trends are well defined. Third, for on-going projects, their project performance data and related causes are available; however, these pieces of information relate to the past. For future performance management and monitoring of the project, appropriate prediction models and cause-and-effect analysis are required. We hope that this paper will provide the motivation for some of this work.

\section{REFERENCES}

[1] Anbari, F.T. (2003). "Earned Value Project Management Method and Extensions." Project Management Journal, PMI, 29(2), 12-23.

[2] Brandon, J. and Daniel, M. (1998). "Implementing Earned Value Easily and Effectively." Project Management Journal, PMI, 29(2), 11-18.

[3] Carey, R.G. and Lloyd, R.C. (1995). Measuring Quality Improvement in Healthcare, Quality Resource, N.Y.

[4] Corbett, C.J. and Pan, J.N. (2002). "Evaluating Environmental Performance using Statistical Process Control Techniques.” European Journal of Operational Research, 139, 68-83.

[5] Daniel, R.M. (1985). "Earned Value Technique for Project Performance.” Journal of Management in Engineering, ASCE, 1(2), 79-94.

[6] Department of Defense (DOD) (1996). Earned Value Management Implementation Guide.

[7] Fleming, Q. and Koppelman, J. (1996). Earned Value Project Management, Project Management Institute, Upper Darby, PA.

[8] Fleming, Q.W. and Koppelman, J.M. (1994). “The Essence of Evolution of Earned Value.” Journal of Cost Engineering, AACE, 36(11), 21-29.

[9] Florac, W.A. and Carleton, A.D. (1999). Measuring the Software Process, Addison-Wesley, Reading, M.A.

[10] Griffith, G.K. (1996). Statistical Process Control Methods for Long and Short Runs, 2nd, ASQC Quality Press, Milwaukee, W.S.

[11] Howes, R. (2000). "Improving the Performance of Earned Value Analysis as a Construction Project Management Tool.” Journal of Construction and Architecture Management, 7(4), 399-411.

[12] Kume, H. (1985). Statistical Methods for Quality Improvement, AOTS, Tokyo, Japan.

[13] Levinson, W.A. and Tumbelty, F. (1997). SPC Essentials and Productivity Improvement: A Manufacturing Approach, ASQ Quality Press, Milwaukee, W.S.

[14] Lipke, W. (2002). "Statistical Process Control of Project Performance." The Measurable News, June, 2002, 25-28. 
Table 4 Summary of Causes Affecting Project Performances

\begin{tabular}{|c|c|c|c|c|c|c|c|c|}
\hline $\begin{array}{c}\text { Pattern Type } \\
\text { for SPI/CPI }\end{array}$ & Freaks & $\begin{array}{c}\text { Gradual } \\
\text { Change in } \\
\text { Level }\end{array}$ & $\begin{array}{c}\text { Grouping } \\
\text { or } \\
\text { Bunching }\end{array}$ & Instability & Interaction & $\begin{array}{c}\text { Natural } \\
\text { Pattern }\end{array}$ & $\begin{array}{c}\text { Sudden } \\
\text { Shift in } \\
\text { Level }\end{array}$ & Trends \\
\hline Administration & $8 / 3$ & $4 / 2$ & $3 / 4$ & $9 / 4$ & $4 / 6$ & $4 / 5$ & $3 / 9$ & $2 / 4$ \\
\hline Budgeting & $2 / 6$ & $0 / 2$ & $2 / 1$ & $5 / 1$ & $2 / 2$ & $5 / 4$ & $4 / 2$ & $3 / 5$ \\
\hline Indemnification & $2 / 1$ & $2 / 1$ & $1 / 1$ & $2 / 1$ & $3 / 3$ & $3 / 4$ & $2 / 5$ & $3 / 2$ \\
\hline Plan \& Design & $6 / 2$ & $2 / 1$ & $3 / 0$ & $2 / 1$ & $2 / 7$ & $6 / 6$ & $3 / 6$ & $2 / 3$ \\
\hline Land Acquisition & $7 / 3$ & $4 / 1$ & $1 / 5$ & $10 / 3$ & $5 / 12$ & $11 / 8$ & $6 / 10$ & $5 / 7$ \\
\hline Bidding Process & $6 / 5$ & $7 / 2$ & $5 / 2$ & $7 / 2$ & $3 / 5$ & $7 / 5$ & $4 / 13$ & $5 / 10$ \\
\hline $\begin{array}{c}\text { Manpower } \\
\text { Demand }\end{array}$ & $1 / 3$ & $0 / 0$ & $1 / 1$ & $3 / 2$ & $2 / 1$ & $6 / 6$ & $4 / 4$ & $1 / 1$ \\
\hline Construction & $28 / 18$ & $10 / 5$ & $18 / 12$ & $13 / 5$ & $12 / 16$ & $36 / 37$ & $22 / 39$ & $12 / 19$ \\
\hline $\begin{array}{c}\text { Acceptance } \\
\text { Activities }\end{array}$ & $4 / 4$ & $2 / 1$ & $5 / 2$ & $4 / 2$ & $1 / 6$ & $8 / 9$ & $8 / 7$ & $3 / 4$ \\
\hline Natural Factors & $5 / 1$ & $4 / 0$ & $2 / 2$ & $3 / 2$ & $1 / 6$ & $6 / 4$ & $5 / 8$ & $6 / 9$ \\
\hline Change Order & $2 / 1$ & $1 / 1$ & $2 / 1$ & $3 / 1$ & $1 / 3$ & $4 / 5$ & $2 / 2$ & $3 / 4$ \\
\hline Others & $2 / 0$ & $1 / 2$ & $1 / 1$ & $0 / 1$ & $3 / 2$ & $2 / 2$ & $1 / 4$ & $2 / 0$ \\
\hline
\end{tabular}

